\title{
INTERTEKSTUAL DALAM NOVEL RAHVAYANA: ADA YANG TIADA KARYA SUJIWO TEJO
}

\author{
Fikha Nada Naililhaq \\ Program Studi Ilmu Sastra, Fakultas Ilmu Budaya \\ Universitas Gadjah Mada, Yogyakarta \\ Fikhanada11@gmail.com
}

\begin{abstract}
ABSTRAK
Penelitian ini bertujuan mendeksripsikan bentuk intertekstual dalam novel Rahvayana karya Sujiwo Tejo dengan Ramayana karya P. Lal. Kedua karya tersebut dipilih karena mempunyai konsep intertekstual. Intertekstual merupakan kajian tentang perbandingan dua teks yang mempunyai kesamaan, satu karya sebagai karya hipogram dan karya lainnya menjadi karya transformasi. Dari penelitian ini, ditemukan bentuk intertekstual melalui karakter tokoh Rahwana, Sinta, dan Rama. Rahwana dan Sinta merupakan tokoh sentral yang memiliki perbedaan karakter dengan teks hipogramnya. Sementara Rama digambarkan dengan karakter yang sama terhadap teks hipogramnya. Selain itu, juga terdapat kebaruan dalam novel Rahvayana yang berhubungan dengan makna filosofisnya.

Kata Kunci: karakter tokoh, makna filosofis, intertekstual, Rahvayana, Ramayana
\end{abstract}

\section{A. PENDAHULUAN}

Karya sastra tercipta sebagai ungkapan ekspresi oleh para penulisnya. Ungkapan ekspresi tersebut dapat berasal dari fenomena kehidupan manusia, pengalaman penulis atau bahkan cerita rakyat, dan sebuah kisah yang pernah ada. Sastra dituangkan melalui bahasa dan tulisan-tulisan yang tidak begitu saja tercipta. Sebuah karya sastra dapat tercipta atas karya-karya sebelumnya. Dengan kata lain, sastrawan menciptakan karya sastra dengan memperhatikan dan mempertimbangkan karya sastra sebelumnya, baik sengaja ataupun tidak sengaja. Unsur ketidaksengajaan muncul karena adanya kesamaan latar belakang sosial budaya sastrawan sehingga memunculkan kemiripan dalam karya sastra. Sementara unsur kesengajaan muncul sebagai referensi pengarang dengan tujuan me mperdalam, mengkritik, ataupun mengembangkan cerita yang te lah ada sebelumnya (Kusdiwantoro, 2017).

Sebagaimana yang diungkapkan oleh Julia Kristeva (da lam Jabrohim, 2003: 126) bahwa setiap teks merupakan mosaik kutipan dan penyerapan (transformasi) teks-teks lain. Hal ini menjelaskan bahwa tiap-tiap teks mengambil sesuatu yang bagus dan menarik dari teks yang telah ada sebelumnya. Dalam hal ini, sebuah karya sastra baru muncul karena menemukan suatu hal yang menarik dari karya sastra lama atau yang telah a da sebelumnya. Konvensi atau gagasan 
tersebut dapat dikenali dengan cara membandingkan teks atau karya sastra baru dengan karya satra yang menjadi hipogramnya.

Sujiwo Tejo merupakan sastrawan yang telah mentransformasi kisah Ramayana menjadi sebuah novel yang berjudul Rahvayana. Rahvayana adalah sebuah dwilogi novel, dengan novel pertama berjudul Rahvayana: Aku Lala Padamu dan novel kedua berjudul Rahvayana: Ada yang Tiada. Sujiw o Tejo dikatakan sebagai seorang sastrawan yang luar biasa dan nyentrik, karena ia merupakan sastrawan yang multitalen, ia bisa mendalang, melukis, dan menciptakan lagu. Sujiwo Tejo bisa mendalang sedari kecil. Pada saat mendalang, ia gemar me langgar pakem cerita yang ada, seperti Rahwana diubah watanya menjadi baik dan Pandawa dibuat tidak selalu benar. Hal tersebut dilakukan Sujiwo tidak hanya pada pentas wayangnya saja, namun dalam menulis novel pun ia melakukan hal demikian, seperti yang terdapat dalam novelnya yang berjudul Rahvayana.

Dalam pene litian ini fokus pada novel Rahvayana jilid dua Ada yang Tiada. Pada novel tersebut terdapat pembongkaran karakter pada tokoh-tokoh yang ada didalamnya. Dimana paling menonjol adalah tokoh Rahwana dan Sinta yang sekaligus menjadi tokoh utama dalam novel. Rahwana menjadi tokoh sentral dengan sudut pandang aku atau orang pertama pelaku utama. Sementara tokoh Sinta merupakan tokoh yang selalu disebut oleh Rahwana karena ia sangat mengagumi dan menc intainya.

Interpretasi tentang Rahwana dalam novel berbanding terbalik dengan kisah yang terdapat dalam buku Ramayana yang ditulis oleh P. Lail. Dalam buku Ramayana, sosok Rawana merupakan raksasa yang angkuh, se lalu dengan perwujudan angkara murka dan dosa-dosa, serta biang pertumpahan darah, dan perebut istri orang. Sementara Rahwana yang terdapat dalam novel Rahvayana merupakan tokoh yang selalu hadir dengan kebaikan sifat dan wataknya. Ketika Rahwana tahu bahwa Sinta sudah menjadi istri Rama, ia merasa sakit hati, namun Rahwana tetap mengagumi Sinta tanpa merebut Sinta dari suaminya. Karakter Sinta juga terdapat perbedaan, dalam buku Ramayana digambarkan sebagai seorang wanita yang selalu memuja suaminya. Walaupun dirinya dipelakukan tidak adil oleh suaminya ia tetap menerima keputusan tersebut tanpa membantah atau protes kepada Rama. Sementara dalam novel Rahvayana, Sinta digambarkan sebagai perempuan feminis yang berani menegakkan keadilan atas dirinya sendiri. 
Novel Rahvayana sangat menarik untuk dikaji, terutama untuk mengetahui sejauh mana pengaruh karya hipogram terhadap karya tranformasi atau karya setelahnya. Oleh sebab itu, penelitian ini menggunakan kajian intertekstual agar dapat membandingkan kedua karya tersebut. Kajian intertekstual dipilih karena dapat digunakan untuk memahami persamaan maupun perbedaan cerita Ramayana dengan Rahvayana. Penelitian ini dilakukan dengan cara menghubungkan kedua karya tersebut.

Berdasarkan uraian pemasalahan diatas dapat diambil sebuah permasalahan dalam penelitian ini yaitu Bagaimana bentuk intertekstual dalam novel Rahvayana: Ada yang Tiada? dan Kebaruan apa yang terdapat dalam novel Rahvayana: Ada yang Tiada? Dengan begitu tujuan dari penelitian ini ada lah mendeskripsikan bentuk intertekstual yang terdapat dalam novel Rahvayana: Ada yang Tiada serta mengungkapkan kebaruan yang terdapat dalam novel Rahvayana: Ada yang Tiada.

\section{B. KAJIAN TEORI}

Kajian intertekstual dapat dikategorikan kedalam resepsi sastra. Resepsi secara luas dapat diartikan sebagai proses produksi teks dangan cara memaknai karya sastra dan memanfaatkan respon pe mbaca terhadapnya (Ratna, 2015: 165). Dalam kajian resepsi sastra terdapat beberapa pendekatan, salah satunya yakni pendekatan intertekstual. Pandangan dalam pendekatan ini pertama digagas oleh Julian Kristeva yang menyatakan bahwa setiap karya tercipta dari hasil transformasi karya sebelumnya atau karya lainnya (Septiyani, 2019). Intertekstualitas dalam karya sastra memiliki arti keterkaitan didalam dua teks sastra yang berbeda. Munculnya keterkaitan itu dipengaruhi oleh faktor eksternal pengarang dan periode lahirnya karya.

Secara luas interteks diartikan sebagai jaringan atau hubungan antara satu teks dengan teks yang lain (Ratna, 2015: 172). Menurut Kristeva dalam Supriyadi (2010: 22) setiap teks dapat diinterpretasikan di dalamnya yang berisi rangkaian kutipan-kutipan. Penulis ketika menciptakan karyanya, ia akan mengambil part dari teks lain yang digunakan sebagai inspirasi karyanya (Purwanti, 2017). Semua itu disusun ulang dan diberi warna dengan berbagai penyesuaian, dapat penolakan atau pembalasan cerita la lu menjadi karya yang utuh. Terciptanya karya sastra melalui transformasi ini dapat muncul karena beberapa alasan. Pertama, tema yang diambil dalam karya sastra tersebut sedang hangat dieranya. Kedua, karya sastra tercipta sebagai

pembalas atau penolakan terhadap jalan cerita pada karya sebelumnya namun tetap pada lingkup 
tema yang sama. Ketiga, karya sastra sebelumnya merupakan karya besar atau epos yang ceritanya banyak diminati oleh masyarakat, misalnya epos rama yana.

\section{METODE PENELITIAN}

Analisis dalam penelitian ini menggunakan novel Rahvayana: Ada yang Tiada karya Sujiwo Tejo sebagai objek material, dengan objek formal kajian intertekstual. Terdapat dua metode penelitia yang digunakan yaitu metode pengumpulan data dan metode analis is data. Metode pengumpulan data yang digunakan yaitu metode studi pustaka, yang dilakukan dengan cara mengumpulkan berbagai data yang relevan dengan data penelitian (Faruk, 2012: 56). Setelah data diperoleh, dilanjutkan analisis data mengunakan metode analisis deskriptif komparatif. Metode ini dilakukan dengan cara menguraikan dan membandingkan data (Ratna, 2015: 34).

\section{HASIL DAN PEMBAHASAN}

Hasil penelitian ini mencakup perbandingan narasi Ramayana dan Rahvayana dengan mengidentifikasi perbedaan dan persamaan diantara keduanya. Kemudian bentuk intertekstual antara Ramayana dengan Rahvayana yang mencakup karakter tokoh Rahwana, Sinta, dan Rama. Serta kebaruan yang terdapat dalam novel Rahvayana yang tidak ada dalam kitab Ramayana. Berikut ini penjabarannya.

\section{Perbandingan Narasi Ramayana dan Rahvayana}

Buku Ramayana yang ditulis oleh P. Lal merupakan rangkuman dari tulisan Walmiki. Jalan cerita yang diungkapkan hampir sama persir, hanya saja terdapat beberapa bagian yang terdapat dalam cerita Walmiki yang tidak dituliskan oleh P. Lal. Buku Ramayana P. Lal terdapat tujuh kanda yang menceritakan kisah Ramayana. Buku ini lebih condong menceritakan tentang kisah hidup Rama.

Rama seorang anak dari Dasarata dan Dewi Kausalya seorang raja di Ayodhya. Rama mengikuti sayembara dan berhasil mempersunting Sita putri raja Janaka sebagai istrinya. Ketika Dasarata akan mengangkat Rama sebagai penggantinya, tidak disetujui oleh Dewi Kakeyi karena ia menginginkan anaknya yang bernama Bharata sebagai penerus Dasarata. Dasarata dengan terpaksa menyetujuinya dan me nyuruh Rama, Sinta, dan Laksmana untuk hidup di hutan selama 14 tahun.

Ketika mereka sudah berada di hutan, ada seorang raksasi bernama Surpanaka yang menginginkan Rama dan Laks mana menjadi suaminya. Akibatnya, hidung dan telinga Surpanaka 
dipotong oleh Laksmana. Surpanaka mengadu kepada kakaknya, Rawana yang menjadi raja raksasa di Alengka, sambil membujuk agar Rawana merebut Sita dari tangan Rama. Atas bantuan Marica yang mengubah diri menjadi kijang keemasan, Sita berhasil diculik Rawana dan dibawa ke Alengka. Burung Jatayu yang berusaha menghalangi penculikan Sita, tewas oleh Rawana. Sebelum tewas, Jatayu masih sempat mengabarkan nasib Sita kepada Rama dan Laksmana yang sedang mencarinya.

Rama dan Laksmana meminta bantuan Sugriwa untuk menye la matkan Sita dari Rawana. Kemudian terjadi kesepakatan diantara keduanya. Sugriwa dan bangsa kurawa membantu Rama menuju Alengka. Hanoman memutuskan untuk ke Alengka terlebih dahulu mencari keberadaan Sita. Ketika bertemu Sita, Hanoman memberikan cincin dan menyuruh Sita untuk ikut dengannya agar bisa bebas dari Rawana dan kembali kepada Rama, namun Sita tidak mau. Ia ingin Rama yang membebaskannya. Kemudian terjadilah perang antara Rama dengan Rawana, dan dimenangkan oleh Rama.

Setelah bertemu Sita, Rama meragukan kesucian Sita. Ia menganggap bahwa Sita telah diperkosa oleh Rawana. Kemudian Sita membuktikan bahwa dirinya masih suci dengan cara dibakar, dan ia pun tidak terbakar sama sekali. Akhirnya Rama percaya, kemudian mereka kembali ke Ayodhya. Penduduk Ayodya mengagumi kekuatan dan keperkasaan Rama yang berhasil mengalahkan raja raksasa. Namun mereka juga menyayangkan kenapa Rama masih pecaya kepada Sita yang telah 12 tahun tinggal bersama Rawana, sehingga mereka berpikir bahwa tidak mungkin Sita masih suci. Rama mendengar rakyatnya bergunjing soal Sita. Akhirnya ia memutuskan untuk membuang Sita ke hutan, tepatnya di padepokan Walmiki. Disana Sita melahirkan anak kembar yang bernama Lawa dan Kusa, kemudian mereka menjadi murid Walmiki.

Pada saat Rama mengadakan upacara Aswameda, Kusa dan Lawa hadir dan menyanyikan kisah Ramayana gubahan Maharsi Walmiki. Kemudian Rama mengetahui bahwa kedua anak tersebut adalah anak kandungnya sendiri, maka dipanggillah Maharsi Walmiki untuk menghantarkan kembali Sita ke istana. Setibanya di istana Sita bersumpah, janganlah hendaknya raganya diterima bumi seandainya ia memang tidak suci, seketika itu pula bumi terbelah dan muncullah Dewi Pertiwi dengan singgasana emas yang didukung oleh ular-ular naga. Sita di peluknya dan dibawanya lenyap ke dalam bumi, Rama sangat menyesal ia pun menyerahkan mahkotanya kepada kedua anaknya. 
Sementara novel Rahvayana yang ditulis oleh Sujiwo Tejo merupakan sebuah novel transformasi dari karya hipogram Ramayana. Dalam novel Rahvayana lebih menonjolkan sisi kehidupan Rahwana sebagai seorang pengagum Sinta. Sinta merupakan sos ok perempuan cantik yang hanya ada da lam angan-angan Rahwana. Namun cara Rahwana menceritakan tentang Sinta membuatnya seolah-olah nyata dan ada. Cerita Rahwana tentang Sinta dapat dilihat dari suratsurat yang ditulisnya. Ketika Rahwana mendengar Sinta telah menikah dengan Rama, ia merasa sakit hati. Walaupun demikian, ia tetap mengirim surat-surat kepada Sinta tanpa merebutnya dari Rama.

Secara garis besar is i surat yang ditulis Rahwana kepada Sinta adalah tentang persiapan serta pementasan keliling dunia teater yang berjudul Rahvayana. Dalam imajinasi Rahwana, ia dan Sinta telah berdiskusi untuk membuat sebuah pertunjukan Rahvayana yang naskahnya ditulis oleh mereka berdua. Rahvayana menghadirkan kembali kisah Ramayana, namun dengan beberapa perbedaan alur, latar, dan karater tokoh yang ada di dalamnya. Perbedaan karakter tokoh yang paling menonjol terdapat pada Rahwana dan Sinta.

Rahwana memiliki sifat yang menyenangkan, baik hati, suka menolong, dan pengagum sejati. Ketika dia sedang mengagumi seorang wanita, dalam hal ini Sinta, ia akan selalu optimis dengan apa yang ia inginkan, contohnya untuk hidup dan menikah bersama Sinta. Walaupun Rahwana tau Sinta sudah menikah, ia tetap menulis surat kepada Sinta dengan harapan Sinta mau membalas surat-suratnya. Sementara Sinta digambarkan sebagai wanita cantik yang kuat dan tangguh serta berani berbicara tentang haknya sebagai istri Rama. Dalam hal ini Sinta menggambarkan gerakan feminisme, sebagai wujud protesnya kepada Rama.

Hampir seluruh kisah dalam novel Rahvayana berkisah tentang Rahwana, Rama, dan Sinta. Berawal dari perja lanan Rahwana ke tembok China, Bali, Siberia, dan Himalaya. Sampai pada kisah Rama (yang terdapat dalam naskah teatar Rahvayana) bertemu dengan Sinta yang telah diasingkannya di hutan Dandaka. Pertemuan antara Rama dan Sinta berkat kedua anak kembarnya Lawa dan Kusa yang berhasil membuat Rama menjadi tidak berdaya. Kemudian Sinta menggugat eksistensi Rama. Sinta meluapkan apa yang telah dialaminya, terutama semua tindakan semena-mena Rama kepadanya. Dalam hal ini Sinta menunjukan adanya gerakan feminis me yang ada da lam dirinya.

Berdasarkan kedua naskah karya sastra di atas, secara garis besar terdapat perbedaan dan persamaan antara karya hipogram dengan karya transformasinya. Dengan demikian kedua teks 
tersebut menunjukan adanya hubungan serta keterkaitan atau biasa disebut dengan intertekstual. Persamaan dari kedua teks tersebut menandakan pengukuhan konvensi yaitu terletak pada nama tokoh dan peristiwa. Se mentara perbedaan yang terdapat pada keduanya menandakan penolakan konvensi yaitu mengenai a lur cerita dan sifat atau karakter tokoh Rahwana dan Sinta.

\section{Bentuk Inte rtekstual antara Ramayana dengan Rahvayana}

Berikut ini akan dijelaskan satu per satu tentang bantuk hubungan intertesktual yang terdapat dalam Ramayana dan Rahvayana. Dari keduanya ditemukan hubungan intertekstual dalam penokohan, khususnya karakter tokoh Rahwana, Sinta, dan Rama yang menjadi tokoh utama dalam novel Rahvayana. Berikut penjelasan mengenai bentuk intertekstual diantara keduanya.

\section{a. Penokohan Rahwana}

Terdapat perbedaan yang mencolok pada karakter tokoh Rahwana yang terdapat pada buku Ramayana dan Rahvayana. Perbedaan tersebut tercermin dari sifat dan perilaku Rahwana. Berikut ini kutipan yang mencerminkan sifat dan perilaku Rahwana pada buku Ramayana.

Mata Rawana mendadak menyala, merah membara. Ia berubah kembali menjadi dirinya. Besar dan mengerikan bagaikan Kala. Dan ia berubah lagi. Kini muncul sepuluh kepalanya dan dua puluh lengannya, terbungkus dalam jubah merah api. Cepat Rawana menyambar Sita. Ia terbakar oleh nafsunya. Tangan kirinya mencekeram rambut Sita, tangan kanan memegang pahanya (Ramayana, 193)

Dari kutipan data diatas menggambarkan tentang keganasan dan kegarangan tokoh Rahwana. Rahwana merupakan seorang Raksasa yang buruk rupa dan mempunyai sifat yang kasar. Terlebih ketika ia marah maka keganasannya akan lebih mengerikan. Dalam cerita Ramayana, dikisahkan bahwa Rahwana awalnya ingin balas dendam kepada Rama, karena ia telah memporak-porandakan rakyatnya. Namun setelah ia mengetahui bahwa istri Rama, yaitu Sinta mempunyai paras yang cantik jelita, maka niatnya pun berubah. Rahwana sangat mengagumi kecantikan Sinta. Ia juga ingin mempersunting Sinta dan menjadikannya permaisuri di kerajaannya.

Awalnya Rahwana menyamar menjadi petapa tua atau brahmana. Dia berbicara kepada Sinta secara baik-baik memperkenalkan dirinya dan maksudnya yang ingin menjadikan Sinta istrinya. Namun mengetahui hal tersebut Sinta langsung menolaknya karena ia ingin setia kepada Rama, suaminya. Penolakan Sinta terhadap ajakan Rahwana membuatnya marah, akhirnya ia 
berubah kewujud as linya menjadi raksasa yang menyeramkan kemudian dengan kasar dan kejam ia me mbawa Sinta pergi ke kerajaanya yaitu kerajaan Alengka.

Penggambaran tokoh Rahwana dalam novel Rahvayana berbeda dengan yang terdapat dalam buku Ramayana. Perbedaan tersebut sangat nyata tergambar dari cerita yang terdapat dalam novel Rahvayana. Rahwana menjadi tokoh utama dalam novel Rahvayana, hal ini menjadikan ia sosok pengaggum sejati yang baik hati dan suka menolong serta memberi kepada orang lain. Rahwana sangat mengagumi dan mencintai Sinta. Kekaguman Rahwana terhadap Sinta tergambar dari surat-surat yang ia tulis kepada Sinta. Surat-surat tersebut berisi isi hati Rahwana kepada Sinta. Bahkan ketika Rahwana mengetahui bahwa Sinta telah menjadi istri Rama ia merasa hancur dan sakit hati. Walaupun Rahwana tau bahwa Sinta sudah memiliki suami namun ia tetap mengaguminya. Rahwana mengagumi Sinta hanya melalui surat-surat yang ditulisnya, ia tidak melakukan tindakan lain selain menulis surat tersebut. Hal ini tercantum dalam ketipan data berikut.

Sinta, hingga sekarang kamu masih belum membalas surat-suratku, kecuali satu surat delapan lembar ungu. Itupun Trijata yang menulis kanya (Rahvayana, 215)

Pada kutipan data di atas terlihat bahwa Rahwana menuliskan surat kepada Sinta untuk kesekian kalinya. Ia menanyakan kenapa Sinta tidak pernah membalas surat-suratnya. Terdapat satu surat balasan, tapi itu pun bukan Sinta yang membalasnya melainkan Trijata. Surat-surat yang dikirimkan Rahwana ibarat cinta yang berulang kali ia tulis dan kirimkan kepada Sinta. Dan Sinta tidak membalas surat-surat Rahwana karena ia juga tidak akan membalas cinta yang telah diungkapkannya.

Kekaguman Rahwana kepada Sinta hanya sebatas surat-surat yang ditulis dan dikirimnya kepada Sinta. Tidak ada tindakan la in yang dilakukan Rahwana untuk mendapatkan cinta dari seorang Sinta. Namun kegigihannya dalam menulis surat tidak tertandingi, karena walaupun surat-surat tersebut tidak pernah dibalas oleh Sinta namun Rahwana tetap menulis dan mengirim surat-surat berikutnya kepada Sinta.

Analisis penokohan Rahwana dalam buku Ramayana dan Rahvayana memiliki perbedaan yang mencolok. Perbedaanya terletak pada sifat dan tindakan Rahwana dalam kehidupan sehari-harinya. Serta ada juga perbedaan tentang cara Rahwana dalam mengagumi Sinta. Dalam Ramayana, kegamuman Rahwana dibuktikan dengan ia menculik Sinta, namun pada Rahvayana kekagumannya hanya tercermin melalui surat-surat. Kemudian untuk 
persamaan diantara keduanya yaitu, tokoh Rahwana digambarkan sebagai sosok yang mengagumi Sinta. Ia se lalu gigih dalam menunjukan kekagumannya namun tetap saja tidak bisa mendapatkan Sinta.

\section{b. Penokohan Sinta}

Sama seperti halnya tokoh Rahwana, tokoh Sinta yang terdapat dalam buku Ramayana dan Rahvayana juga berbeda. Perbedaan tersebut terletak pada ucapan, tindakan, dan keberanian Sinta terhadap Rama. Dalam buku Ramayana diceritakan bahwa Sinta merupakan perempuan yang cantik jelita dan selalu mendewakan suaminya. Ia selalu mengikuti kemanapun suaminya pergi dan selalu menurut tentang apa yang telah diperintahkan oleh suaminya. Walaupun Sinta tahu bahwa suaminya telah berbuat semena-mena kepadanya.

Beberapa perbuatan semena-me na yang dilakukan Rama seperti, ia tidak percaya kepada Sinta yang masih suci setelah diculik oleh Rahwana, kemudian Rama menyuruh Sinta untuk masuk ke dalam kobaran api. Kemudian setalah sampai di A yodhya penduduknya banyak yang menggunjing Sinta, sehingga Rama merasa risih karena gunjingan rakyatnya. Akhirnya Rama memutuskan untuk membuang Sinta ke hutan, padahal ketika itu Sinta sedang hamil anak Rama. Setelah itu ada juga terdapat peristiwa ketika Rama ingin pembuktian Sinta yang kedua kalinya dihadapan para penduduk Ayodhya bahwa ia tidak dijamah oleh Rahwana. Sinta mengucapkan mantra yang ditujukan kepada Dewi Bumi sebagai pe mbuktiannya, seperti pada kutipan berikut.

Begitu Sita selesai mengucapkan kata-katanya, tiba-tiba bumi dihadapan Sita terbelah. Dewi Bumi muncul dihadapan Sita. Sang Dewi memeluk Sita, mendekapnya dengan hormat mendudukkannya di takhta dewata itu. Perlahan-lahan disaksikan para dewa, takhta dengan Sita duduk di atasnya itu turun masuk ke dalam perut bumi, ke bumi Rasatela. Dan bumi menutup kembali. Dan seluruh bumi gemetar keras (Ramayana, 391392)

Dari kutipan di atas, menunjukan bahwa Sinta mengucapkan mantra yang menyatakan bahwa jika ia tidak bersalah maka ia bumi akan terbe lah dan ia akan masuk ke dalam bumi. Hal itu pun terjadi, karena Sinta tidak bersalah maka ia dijemput oleh Dewi Bumi untuk masuk ke dalam perut bumi. Hal ini menunjukan peristiwa yang kesekian kalinya Sinta menuruti kemauan Rama tanpa protes sedikitpun. Ia juga tidak mengucap sepatah kata apapun untuk membela dirinya dengan meyakinkan Rama dan pendudk Ayodhya, namun ia langsung membuktikan tentang kesuciannya dan tidak benar tuduhan rakyat tersebut. 
Sinta dalam Rahvayana juga berbeda dari Sinta yang terdapat dalam Ramayana. Sinta dalam Rahvayana digambarkan sebagai perempuan yang berani mempertanyakan keadilan tentang dirinya. Sinta perempuan yang tangguh, ia bukan seorang perempuan yang hanya menuruti kemauan Rama meskipun itu tidak adil baginya. Sudah muncul sisi feminisme dari diri Sinta untuk berjuang melawan bentuk ketidakadilan yang telah dilakukan oleh Rama. Ketangguhan Sinta mulai tergambar pada saat ia dibuang di hutan ketika sedang hamil, ia merawat kandungannya seorang diri di padepokan Walmiki. Sampai akhirnya ia melahirkan dua anak kembar yang bernama Lawa dan Kusa yang kelak menjadi ksatria yang sangat hebat dan susah dika lahkan.

Selain itu, Sinta juga melakukan tindakan untuk menggugat perbuatan Rama yang se lama ini telah berbuat semena-mena kepadanya. Tindakan yang dilakukan Sinta yaitu dengan cara mengungkapkan keluh kesah apa yang selama ini ia rasakan kepada Rama, tentang apa yang dialaminya. Hal ini tercermin dalam kutipan data berikut.

Dengan garis-garis ketuaan yang masih menjejakkan kecantikanmu, lirih, tapi tegas, kamu berucap kepada Rama, "Ya, Rama, jika kamu mas ih pangling dengan aku, sekarang akan kuakui saja, akulah Sinta yang me mbesarkan anak-anakku di rimba kehidupan keras dan ganas ini .... Tanpa seorang ayah ...." (Rahvayana, 231)

Kutipan data di atas menjelaskan tantang keberanian Sinta menggugat Rama atas apa yang telah ia perbuat kepada Sinta. Sinta menunjukan bahwa ia wanita kuat, bisa hidup dalam hutan rimba seorang diri dan membesarkan kedua anaknya yaitu Lawa dan Kusa. Sampai akhirnya kedua anaknya menjadi seorang kesatria kuat bahkan sampai mengalahkan Rama. Dan berkat anaknya tersebut akhirnya Rama dapat bertemu Sinta. Keberanian Sinta dalam mengungkapkan isi hatinya yang telah lama dipendam menandakan bahwa Sinta bukanlah perempuan lemah yang tertindas tanpa bisa berbuat apa-apa. Sinta diwujudkan sebagai seorang feminis yang telah memiliki kesadaran atas penindasan yang dialaminya, sehingga ia berani untuk berbicara dan menggugat Rama atas ketidakadilan dan kesewenang-wenangannya terhadap Sinta selama ini.

Analisis penokohan Sinta dalam buku Ramayana dan Rahvayana memiliki perbedaan sifat dan tindakan. Perbedaan tersebut tercermin keberanian Sinta pada Rahvayana ketika menggungat Rama untuk mencapai keadilan akan dirinya. Sementara Sinta pada Ramayana memiliki sifat yang patuh dan mendewakan suaminya tanpa membantah dan tidak berbuat apa- 
apa ketika diberlakukan tidak adil oleh Rama. Persamaan diantara kedua buku yaitu Sinta pernah menga lami bentuk ketidakadilan yang dilakukan Rama.

\section{c. Penokohan Rama}

Berbeda dengan tokoh Rahwana dan Sinta, penggambaran tokoh Rama dalam buku Ramayana dan Rahvayana memiliki persamaan karakter. Rama digambarkan sebagai seorang brahmana yang memiki istri bernama Sinta. Sinta yang cantik jelita membuat semua orang menyukainya, termasuk Rahwana yang tergila-gila pada Sinta. Rama juga digambarkan sebagai orang yang tidak percaya akan kesucian Sinta, padahal Sinta selalu menjaga kesuciannya untuk Rama. Rama melakukan berbagai bentuk ketidakadilan yang selalu memojokkan Sinta, sehingga Sinta harus menerima pelakuakan ketidakadilan dari suaminya tersebut.

Dalam Rahvayana tokoh Rama bukanlah tokoh utama, ia hanya tokoh sampingan yang hanya diceritakan sekilas. Sehingga tidak banyak data-data mengenai Rama dalam novel tersebut. Berbeda dengan Ramayana yang menjadikan Rama sebagai tokoh utamanya. Sehingga kisahnya fokus pada kisah hidup Rama. Mulai dari Rama kecil sampai ia menikah dengan Sinta, dan akhirnya Rama kembali ke rimba karena kehilangan Sinta akibat ulahnya sendiri.

\section{Kebaruan Makna Filosofi dari Novel Rahvayana}

Dari penjelaskan yang telah dipaparkan sebelumnya, terbukti bahwa novel Rahvayana karya Sujiwo Tejo memiliki hubungan intertekstual dengan buku Ramayana karya P. Lal. Novel Rahvayana menjadi karya tranformasi atau adaptasi dari kisah Ramayana, maka tidak menutup kemungkinan bahwa terdapat kebaruan dari karya hipogramnya. Kebaruan ini sangat menonjol pada makna filosofi novelnya. Makna filosofi pada novel tersebut terdapat pada tokoh Sinta. Sinta da lam novel Rahvayana digambarkan ada yang tiada atau antara ada dan tidak ada. Tokoh Sinta diibaratkan sebagai Tuhan, Dia tidak terlihat namun Dia ada. Dia tidak ada dalam kehidupan nyata, namun Dia ada di hati dan pikiran manusia yang diwakilkan oleh tokoh Rahwana.

Rahwana ibarat hamba yang selalu mengagug-agungkan Tuhan, dan selalu menghadikan Nya dalah kehidupan sehari-hari. Rahwana bisa disebut sebagai gambaran hamba yang taat kepada Tuhannya. Hal ini terlihat dari alur cerita kehidupan sehari-harinya yang selalu menempatkan Sinta dalam hal ini Tuhan dalam setiap langkah kesehariannya. Dalam suka maupun duka Rawana akan menuliskan dan mengadu kepada Tuhan apa yang telah diewati dan dialaminya. Dengan harapan ia akan mencapai kemauan atau cita-cita yang diimpikan. 


\section{E. KESIMPULAN}

Dalam buku Ramayana dan Rahvayana terdapat intertekstual diantara keduanya. Bentuk intertekstual dapat dilihat dari persamaan dan perbedaan diantara keduanya. Persamaan dan perbedaan tersebut tercermin pada tiga tokoh yaitu Rahwana, Sinta, dan Rama. Perbedaan menonjol tergambar pada sifat Rahwana dan Sinta, sementara persamaan tergambar pada Rama. Dalam Rahvayana, Rahwana mempunyai sifat pengagum sejati yang baik hati dan suka menolong serta memberi kepada orang lain. Kemudian Sinta digambarkan sebagai perempuan yang pemberani, ia berani menggugat Rama atas ketidakadilan yang diperolehnya dari Rama. Sedangkan Rama digambarkan sebagai brahmana yang tampan dan bijaksana yang mempunyai istri bernama Sinta yang cantik jelita. Perbedaan terhadap keduanya dapat dikatakan sebagai bukti dari penolakan konvensi yang dilakukan pengarang. Sementara persamaan dikatakan sebagai pengukuhan konvensi yang dilakukan oleh pengarang dalam hal ini yaitu Sujiwo Tejo. Dalam Rahvayana juga terdapat sebuah kebaruan yang berupa makna filsafat. Sinta diibaratkan sebagai Tuhan yang tidak nampak namun tetap selalu dihati hambanya atau disebut sebagai ada yang tiada. Rahwana adalah simbol dari seorang hamba yang selalu mengingat Tuhan disetiap kehidupannya.

\section{F. SARAN}

Berdasarkan kesimpulan dalam penelitian ini, peneliti memberikan saran kepada pembaca untuk lebih memahami karya-karya besar atau epos yang ada di Indonesia. Hal ini akan menambah wawasan bagi mereka mengenai karya sastra terdahulu yang sampai sekarang masih populer. Sehingga apabila pembaca membaca karya sastra baru maka ia akan mengetahui apakah karya sastra tersebut memiliki hubungan dengan karya sastra terdahulu atau tidak. Dengan demikian akan menjadikan pembaca mempunyai wawasan yang luas.

\section{DAFTAR PUSTAKA}

Faruk. 2012. Metode Penelitian Sastra. Yogyakarta: Pustaka Pelajar.

Jabrohim. 2003. Beberapa Teori Sastra. Yogyakarta: Hanindita Graha Media.

Kusdiwantoro, Arif. 2017. Kajian Intertekstual Penokohan Rahwana dalam Novel "Rahvayana" Karya Sujiwo Tejo dan Implementasinya sebagai Bahan Ajar Sastra di SMP 2 Matesih (Skripsi, Universitas Muhammadiyah Surakarta) Retrived from eprints.ums.ac.id.

Lal, P. 2008. Ramayana. Bogor: Pustaka Jaya. 
Purwanti. 2017. Dekonstruksi Penceritaan dalam Novel Arok Dedes: Kajian Intertekstual. Atavisme, 20(2), 197-210.

Ratna, Nyoman Kutha. 2015. Teori, Metode, dan Teknik Penelitian Sastra. Yogyakarta: Pustaka Pelajar.

Septiyani, Vandika Indah \& Sayuti, Suminto A. 2019. Oposisi dalam Novel Ruhuvana Tattwa Karya Agus Sunyto: Analis is Intertekstual Julia Kristeva. Lensa, 9(2), 174-186.

Supriyadi, Ahmad. 2010. Transformasi Nilai-nilai Ajaran Islam dalam Ayat-ayat Cinta karya Habibirrahman El-Shirazy: Kajian interteks (Thesis, Universitas Diponegoro). Retrie ved from eprints.undip.ac.id

Tejo, Sujiwo. 2015. Rahvayana: Ada yang Tiada. Jakarta: Mizan Digital Publishing. 